\title{
ANALISIS FINANSIAL PENGGUNAAN LAMPU PETROMAK SEBAGAI PEMANAS PADA BUDIDAYA PEMBENIHAN IKAN PATIN
}

\author{
lis Diatin1 dan Ganang Arytra Dwirosyadha² \\ ${ }^{1}$ Staf pengajar Dept. Budidaya Perikanan,Fakultas Perikanan IImu Kelautan, IPB \\ ${ }^{2}$ Alumni Dept. Sosial Ekonomi Perikanan, Fakultas Perikanan dan IImu Kelautan, IPB
}

\begin{abstract}
ABSTRAK
Kegiatan pembenihan ikan patin, terutama dalam usaha skala kecil pada umumnya menggunakan kompor minyak tanah sebagai pemanas ruangan, agar tingkat kematian benih dapat ditekan. Kenaikan harga minyak tanah akhir-akhir ini, bahkan hilangnya minyak tanah di beberapa tempat, menjadi kendala dalam kegiatan pembenihan ikan patin ini. Oleh karena itu perlu dicari alternatif teknologi pengganti yang lebih efisien dalam penggunaan minyak tanah; dalam hal ini, menggunakan lampu petromak. Sehingga penelitian ini bertujuan untuk menganalisis secara finansial penggunaan lampu petromak sebagai pemanas ruangan pembenihan. Hasil analisis menunjukkan bahwa selama setahun dengan menggunakan kompor minyak tanah mampu memperoleh keuntungan sebesar Rp 52.996.455,56, nilai R/C sebesar 1,97 dan payback period selama 1,73 tahun. Sedangkan analisis usaha dengan menggunakan lampu petromak, diperoleh keuntungan sebesar Rp. 60.556.455,56, nilai R/C sebesar 2,28 dan payback period selama 1,52 tahun. Analisis finansial menghasilkan nilai NPV sebesar Rp 695.550.355,5, Net B/C sebesar 27,69\% dan nilai IRR $457,26 \%$. Usaha pembenihan ikan patin dengan menggunakan pemanas lampu petromak ini menjadi tidak layak untuk diusahakan jika terjadi kenaikan harga minyak tanah sebesar $1.161,87 \%$, kenaikan harga pakan sebesar $1.228,65 \%$ dan penurunan harga benih sebesar $98,57 \%$.
\end{abstract}

Kata Kunci: Analisis Finansial, Lampu Petromak, Pembenihan, Ikan Patin

\section{Abstract : Financial Analysis of the used 'Petromak' as a Heater in Catfish Hatchery By: lis Diatin and Ganang Arytra Dwirosyadha}

Catfish hatchery, especially in small-scale business is generally using primus stove as column heater in order to reduce mortality of seed produced. An increase in the price of kerosene recently, even the dissapearing kerosene in some place, has been becoming a constraint in this catfish hatchery. Therefore, an alternative technology by using 'petromak' in order to reduce the use of kerosene was taken into place. So that, this research was aimed to analyse financially the use of petromak lamp as room heater in hatchery. Results showed that the use of primus stove in hatchery enables to generate profit of $R p 52,996,455.56$, a $R C$-ratio of 1.97 and payback period of 1.73 years. Meanwhile, the use of 'petromak' lamp enables to generate profit of $R p 60,556,455.56$, a RC-ratio of 2.28 and payback period of 1.52 years. Financially, the latter produces NPV of Rp 695,550,355.5, net BC-ratio of $27.69 \%$ and IRR of $457.26 \%$. The business will be loss whenever price of kerosene increases $1,161.87 \%$ or price of feed increases $1,228.65 \%$ or price of seed decreases $98.57 \%$.

Keywords: Financial Analysis, Petromak Lamp, Hatchery, Catfish 


\section{PENDAHULUAN}

Ikan patin merupakan salah satu jenis ikan air tawar yang memiliki nilai ekonomis yang tinggi. Keunggulan ikan patin dibandingkan dengan ikan air tawar lainnya adalah tidak memiliki sisik dan mempunyai duri sedikit, sehingga mudah dikonsumsi. Keberhasilan usaha ikan patin konsumsi sangat didukung oleh ketersediaan benih yang memadai (Efendi dan Oktariza, 2006). Usaha pembesaran ikan patin untuk konsumsi banyak diusahakan di wilayah Sumatera dan Kalimantan, sedangkan usaha pembenihannya banyak dilakukan di daerah Bogor dan sekitarnya (Sunarma, 2008).

Pengelolaan pembenihan ikan patin pada umumnya masih tergolong sederhana, seperti sistem pemanas ruangan yang masih menggunakan kompor minyak tanah, sistem sirkulasi air sederhana, dan lain-lain. Untuk meningkatkan kualitas dan kuantitas output yang dihasilkan, salah satu upayanya adalah dengan mengganti teknologi yang ada dengan teknologi yang lebih efisien. Pemanas ruangan dalam kegiatan pembenihan ikan patin sangat berpengaruh dan sangat penting terhadap hasil produksi benih patin (Susanto dan Amri, 1999). Hal ini disebabkan karena suhu merupakan salah satu faktor penting dalam kesuksesan pembenihan ikan. Jika suhu berubah dan tidak sesuai dengan suhu optimal, maka benih ikan terancam mati dalam jumlah yang sangat besar.

Pemanas ruangan yang umum digunakan dalam kegiatan pembenihan ini yaitu dengan menggunakan kompor minyak tanah. Saat ini pengunaan kompor minyak tanah menjadi kendala, karena ketersediaan minyak tanah yang langka bahkan hampir tidak ada serta harganya yang meningkat tajam (dari Rp 2.700,00 pada tahun 2007 menjadi Rp 10.000,00 pada April 2008). Hal ini menyebabkan biaya produksi semakin melonjak. Salah satu solusi dalam upaya menekan biaya tersebut yaitu dengan mengganti sistem pemanas ruangan pembenihan yang menggunakan kompor minyak tanah dengan menggunakan lampu tekan petromak. BPPT pada tahun 2006 lalu telah melakukan riset terhadap pengganti penggunaan minyak tanah dengan menggunakan petromak sebagai objek riset. Tujuan riset tersebut adalah untuk mencari alternatif penggunaan bahan bakar yang lebih hemat dan efisien. Petromak memiliki kelebihan yaitu konsumsi bahan bakar lebih hemat, daya tahan lebih lama, dan perawatan lebih mudah (BPPT, 2006).

Penggantian teknologi pemanas dari kompor minyak tanah dengan lampu petromak pada kegiatan pembenihan ikan patin ini diharapkan akan menekan biaya produksi, sehingga akan meningkatkan jumlah keuntungan yang diperoleh pembenih ikan patin. Sebelum penggantian teknologi ini dilakukan, maka perlu dilakukan kajian, apakah penggantian ini layak untuk dilakukan. Penelitian ini dilakukan dengan mengambil kasus pada salah satu tempat pembenihan ikan patin di Kabupaten Bogor yaitu Nusa Hias Farm. Tujuan dari penelitian ini adalah menganalisis kelayakan finansial penggunaan lampu petromak sebagai pemanas ruangan dan mengetahui sensitivitas penggunaan lampu petromak ini dalam usaha pembenihan ikan patin tersebut.

\section{METODOLOGI}

Metode penelitian yang digunakan adalah studi kasus dengan satuan kasusnya adalah usaha pembenihan ikan patin Nusa Hias Farm yang berlokasi di Desa Cibitung Tengah Kecamatan Ciampea, Kabupaten Bogor. Penelitian ini dilakukan hanya pada satu perusahaan dengan pertimbangan bahwa usaha pembenihan ikan patin di Desa Cibitung Tengah yang dikelola oleh perorangan, dengan penanganan yang masih tradisional serta menggunakan sarana dan prasarana yang masih sederhana terdapat di Nusa Hias Farm. 
Berdasarkan sumbernya, data yang dikumpulkan dalam penelitian ini terdiri dari data primer dan data sekunder. Data primer diperoleh dari observasi dan wawancara langsung pengelola Nusa Hias Farm. Sedangkan data sekunder diperolah dari studi pustaka dan instansi terkait (BPPT, dll).

Analisis data yang digunakan dalam penelitian ini adalah sebagai berikut:

\section{A. Analisis Usaha Pembenihan ikan Patin}

Kegiatan pembenihan ikan patin sebagai suatu aktivitas usaha akan selalu terkait dengan biaya yang harus dikeluarkan dengan penerimaan yang akan diperoleh (Rahardi et.al., 2005). Menurut Gittinger (1986), biaya yang harus dikeluarkan dalam usaha tani meliputi biaya tetap (fixed cost) dan biaya berubah (variable cost).

Menurut Kadariah et al. (1978), suatu usaha yang memerlukan modal yang besar dengan resiko yang besar diperlukan suatu analisis kelayakan usaha. Analisis kelayakan usaha dumaksudkan untuk mengevaluasi apakah usaha tersebut layak untuk diusahakan. Untuk mengevaluasi kelayakan usaha perlu diketahui besar manfaat dan besar biaya dari setiap unit yang dianalisis. Indikator yang dapat dipakai untuk membandingkan manfaat dan biaya pada usaha yaitu NPV, Net B/C dan IRR Kegiatan usaha dikatakan layak untuk dikembangkan jika dalam perhitungannya diperoleh NPV >0, $\mathrm{IRR}>$ discount rate, Net B/C>1.

\section{Analisis Keuntungan}

$$
\pi=\mathrm{TR}-\mathrm{TC}
$$

Dimana: $\pi=$ Keuntungan/Profit

TR = Penerimaan total usaha / Total Revenue

$\mathrm{TC}=$ Biaya total usaha / Total Cost

\section{Analisis Imbangan Penerimaan dan Biaya} (R/C).

$$
\mathrm{R} / \mathrm{C}=\mathrm{TR} / \mathrm{TC}
$$

Dengan kriteria usaha :

$\mathrm{R} / \mathrm{C}>1$, maka usaha menguntungkan/

$$
\text { Profitable }
$$

$\mathrm{R} / \mathrm{C}=1$, maka usaha impas $/$ Paid off

$\mathrm{R} / \mathrm{C}<1$, maka usaha rugi/Lose out

\section{Analisis Waktu Pengembalian Modal}

(Payback Period, PP)

$P P=\frac{\text { Investasi }}{\text { Keuntungan }} \times$ tahun

\section{B. Analisis Kelayakan Finansial}

Untuk mengetahui kelayakan finansial dari usaha pembenihan ikan patin ini diperlukan data seperti besarnya manfaat atau benefit dan besarnya biaya dari setiap unit yang dianalisis. Dalam menghitung besarnya manfaat dan biaya, maka dalam analisis ini menggunakan asumsi -asumsi sebagai berikut:

1. Umur proyek selama 10 tahun.

2. Usaha tanpa proyek adalah usaha pembenihan ikan patin dengan menggunakan kompor minyak tanah sebagai pemanas ruangan.

3. Sumber modal yang digunakan dalam proyek berasal dari modal sendiri.

4. Harga benih ikan patin ukuran 1 inch adalah Rp90,00 per ekor dan ukuran 3 inch adalah Rp375,00 per ekor.

5. Produksi patin ukuran 1 inch adalah sebesar $70 \%$ dan benih ukuran 3 inch adalah sebesar 30\%.

6. SR benih adalah $80 \%$ dan Derajat penetasan telur (HR) sebesar $30 \%$.

7. Discount rate yang digunakan berdasarkan suku bunga deposito bank BNI sebesar $10,8 \%$ per tahun.

8. Analisis sensitivitas dilakukan dengan menggunakan tiga skenario, yaitu kenaikan harga pakan benih, kenaikan harga minyak tanah dan penurunan harga penjualan benih ikan patin.

Menurut Kadariah et al. (1978), indikator yang digunakan untuk membandingkan manfaat dan biaya pada usaha adalah sebagai berikut: 
1. Net Present Value (NPV)

$$
N P V=\sum_{t=0}^{10} \frac{B t-C t}{(1+i)^{t}}
$$

Dimana: $\mathrm{Bt}=$ Manfaat dari usaha pada tahun ke-t/ Benefit

$\mathrm{Ct}=$ Biaya dari usaha pada tahun ke-t/Cost

$\mathrm{i}=$ Tingkat suku bunga (digunakan BNI sebesar $10,8 \% /$ Interest Rate

$\mathrm{t}=$ Tahun usaha $(\mathrm{t}=10$ tahun $) /$ Year

Kriteria kelayakan dalam metode NPV adalah:

NPV $>0$, Maka proyek menguntungkan/ Profitable

$\mathrm{NPV}=0$, Maka proyek tidak menguntungkan tapi juga tidak rugi, jadi tergantung penilaian subyektif pengambilan keputusan/Paid off

$\mathrm{NPV}<0$, maka proyek merugikan karena keuntungan lebih kecil daripada biaya/Lose out

2). Net Benefit-Cost Ratio(Net B/C)

$$
N e t B / C=\frac{\sum_{t=0}^{10} \frac{B t-C t}{(1+i)^{t}}}{\sum_{t=0}^{10} \frac{C t-B t}{(1+i)^{t}}}
$$

Kriteria kelayakan pada metode ini adalah:

Net $B / C>1$, proyek dianggap layak

Net $B / C=1$, merupakan titik impas

Net $B / C<1$, proyek tidak layak

3). Internal Rate of Return (IRR)

$$
N P V^{\prime}
$$

$$
I R R=i^{\prime}+\frac{}{N P V^{\prime}-N P V^{\prime \prime}} \quad i^{\prime \prime}\left(i^{\prime}\right)
$$

Dimana: NPV = NPV positif pada suku bungai'

$$
\begin{aligned}
\text { NPV }= & \text { NPV negatif pada suku } \\
& \text { bunga i" } \\
i^{\prime}= & \text { tingkat bunga dimana } \\
& \text { NPV bernilai positif } \\
\mathrm{i}^{\prime}= & \text { tingkat bunga dimana } \\
& \text { NPV bernilai negatif }
\end{aligned}
$$

Dengan kriteria usaha:

IRR $>$ i, usaha dapat dilanjutkan

IRR $<\mathrm{i}$, usaha lebih baik ditolak

\section{Analisis Sensitivitas}

Metode yang digunakan dalam analisis usaha pembenihan ikan patin adalah metode switching value dan komponen yang dianalisis adalah kenaikan harga minyak tanah, kenaikan harga pakan benih dan penurunan harga benih ikan patin

\section{HASIL DAN PEMBAHASAN}

\subsection{Teknis Pembenihan Ikan Patin}

Kegiatan usaha pembenihan ikan patin pada Nusa Hias Farm dapat digambarkan pada Gambar 1:

Pemeliharaan Induk/Brood Stock

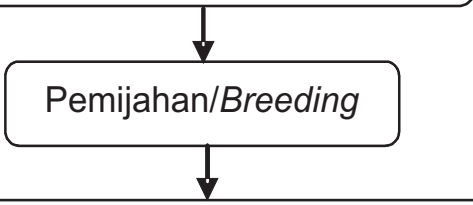

Pemeliharaan larva dan benih/Nursery

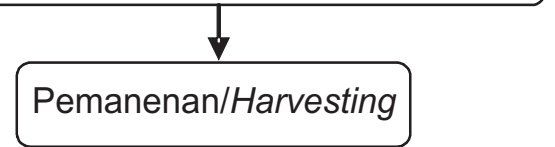

Gambar 1. Alur Teknis Pembenihan Ikan Patin Nusa Hias Farm.

Figure 1. Technical Flow of Catfish Hatchery in Nusa Hias Farm.

\section{(1) Pemeliharaan induk}

Induk jantan dan betina dipelihara di kolam dengan kepadatan 3-5 ekor/ $\mathrm{m}^{2}$. Induk dibagi dalam beberapa kelompok dan dipelihara secara terpisah, dengan kualitas air untuk induk adalah suhu $25-30{ }^{\circ} \mathrm{C}$ dan $\mathrm{pH}$ 6,0- 
8,5. Pakan yang diberikan berupa pakan buatan berupa pelet dengan pemberian pakan dilakukan setiap hari sebanyak $3 \%$ bobot biomas/hari dan frekuensi pemberian pakan 2$3 \mathrm{kali} / \mathrm{sehari}$.

\section{(2) Pemijahan}

Pemijahan dilakukan dengan pemijahan buatan. Sebelum dilakukan pemijahan, induk ikan patin disuntik terlebih dahulu dengan menggunakan hormon di kelenjar hipofisia ikan mas. Penyuntikan dilakukan dua kali. Setelah 5-10 jam dari waktu penyuntikan dilakukan stripping untuk mengeluarkan telur dan sperma. Telur dan sperma dicampur merata, kemudian ditebarkan di bak penetasan. Telur akan menetas sekitar 18-24 jam.

\section{(3) Pemeliharaan larva dan benih}

Telur yang menetas menjadi larva harus dirawat dengan baik. Larva yang baru berumur satu hari belum diberi makan, karena masih memiliki cadangan makanan. Pakan pertama diberikan berupa Naupili Artemia. Pemeliharaan larva atau benih di akuarium dilakukan sampai umur minimal 10-14 hari sebelum dipindahkan ke dalam bak pendederan. Sedangkan pemindahan benih dari bak ke kolam dilakukan setelah pemeliharaan 3-4 minggu. Benih ikan patin memiliki survival rate (SR) berkisar antara $80 \%$ - $90 \%$ dari total benih. Dalam pemeliharaan ini suhu harus selalu dijaga agar ruangan tetap stabil, dengan menggunakan kompor minyak tanah.
Alternatif untuk mengganti sistem pemanas ruangan kompor minyak tanah ini, yaitu dengan menggunakan petromak. Panas yang dihasilkan petromak dapat memenuhi kebutuhan panas yang dibutuhkan dalam proses pembenihan guna menjaga kestabilan suhu.

\section{(4) Pemanenan}

Benih siap dipanen setelah pemeliharaan selama 4-5 minggu, dengan ukuran benih yang dihasilkan $1-3$ inch.

\subsection{Analisis Usaha Pembenihan Ikan Patin}

\section{(1) Analisis Keuntungan Usaha}

Penerimaan dari kegiatan pembenihan ikan patin berasal dari nilai produksi benih ikan patin selama kurun waktu setahun. Persentase produksi yang dihasilkan dari kegiatan pembenihan pada Nusa Hias Farm adalah sekitar $70 \%$ benih ukuran 1 inch dan $30 \%$ benih ukuran 3 inch. Rincian penerimaan usaha pembenihan ikan patin Nusa Hias Farm dapa dilihat pada Tabel 1.

Investasi yang dikeluarkan dalam usaha pembenihan ikan patin dengan menggunakan pemanas kompor minyak tanah adalah sebesar Rp 91.592.500,00, sedangkan investasi dengan menggunakan pemanas lampu petromak adalah sebesar Rp 92.242.500,00. Perbedaan nilai investasi ini disebabkan karena pembelian lampu petromak lebih mahal dibandingkan dengan kompor minyak tanah.

Tabel 1. Penerimaan Usaha Pembenihan Ikan Patin Nusa Hias Farm, 2008

Table 1. Revenue of the Catfish Hatchery in Nusa Hias Farm, 2008

\begin{tabular}{lccr}
\hline $\begin{array}{l}\text { Ukuran Benih Ikan/ } \\
\text { Size of Seed }\end{array}$ & $\begin{array}{c}\text { Harga Jual/ekor/ } \\
\text { (Rp/Price)/Price/seed }\end{array}$ & $\begin{array}{c}\text { Output per Tahun (ekor)/ } \\
\text { Output per Year (seed) }\end{array}$ & Total (Rp) \\
\hline 1 inch $(2,54 \mathrm{~cm})$ & 90,00 & 430.080 & $38.707 .200,00$ \\
3 inch $(7,63 \mathrm{~cm})$ & 375,00 & 184.320 & $69.120 .000,00$ \\
Total Penerimaan/Total Revenue & & $\mathbf{6 1 4 . 4 0 0}$ & $\mathbf{1 0 7 . 8 2 7 . 2 0 0 , 0 0}$ \\
\hline
\end{tabular}


Jumlah biaya tetap yang dikeluarkan dengan penggunaan pemanas kompor minyak tanah adalah sebesar Rp 46.083.600,00, dan biaya variabel sebesar Rp 8.747.144,44. Jumlah total biaya yang dibutuhkan selama setahun adalah sebesar Rp 54.830.744,44. Sedangkan dengan penggunaan lampu petromak jumlah biaya tetap yang dibutuhkan adalah sebesar Rp 38.523.600,00 dan biaya variabel sebesar Rp 8.747.144,44. Sehingga biaya total yang diperlukan selama setahun adalah sebesar Rp 7.270.744,44. Biaya total yang dikeluarkan dalam usaha ini disebabkan karena penggunaan bahan bakar pada lampu petromak lebih hemat dan lebih efisien sehingga bisa menekan biaya yang dikeluarkan. Adanya penghematan biaya ini juga menyebabkan penggunaan lampu petromak lebih menguntungkan. Hasil keuntungan yang diperoleh pada penggunaan kompor minyak tanah keuntungan yang diperoleh sebesar Rp 52.996.455,56. Sedangkan pada penggunaan lampu petromak keuntungannya sebesar Rp 60.556.455,56 (Tabel2).

(2) Analisis Imbangan Penerimaan dan Biaya (R/C)

Analisis $\mathrm{R} / \mathrm{C}$ dilakukan untuk mengetahui berapa besar usaha pembenihan ikan patin ini memberikan keuntungan pada periode tertentu. Nilai R/C yang diperoleh dari usaha pembenihan ikan patin dengan menggunakan pemanas kompor minyak tanah adalah sebesar 1,97 dan R/C dengan menggunakan pemanas lampu petromak sebesar 2,28. Nilai ini menunjukkan bahwa dari setiap satu rupiah biaya yang dikeluarkan, akan memperoleh penerimaan sebesar Rp 1,97 pada penggunaan kompor minyak tanah dan Rp 2,28 pada penggunaan lampu petromak. Dengan demikian penggunaan lampu petromak memberikan nilai penerimaam yang lebih tinggi dibandingkan dengan kompor minyak tanah.

\section{(3) Analisis Waktu Pengembalian Modal (Payback Period)}

Analisis Payback Period (PP) bertujuan untuk mengetahui berapa lama waktu yang diperlukan untuk mengembalikan investasi yang ditanamkan pada usaha pembenihan ikan patin ini. Nilai Payback Period (PP) pada usaha pembenihan dengan menggunakan pemanas kompor minyak tanah diperoleh nilai sebesar 1,73 tahun, dan dengan menggunakan pemanas lampu petromak sebesar 1,52 tahun. Jadi penggunaan lampu petromak lebih cepat mengembalikan investasi yang ditanamkan dibandingkan dengan penggunaan kompor minyak tanah.

Tabel 2. Analisis Usaha Pembenihan Ikan Patin dengan Pemanas Minyak Tanah dan Lampu Petromak Nusa Hias Farm, 2008.

Table 2. Analysis of Catfish Hatchery by Using Primus Stove and 'Petromak' Lamp in Nusa Hias Farm, 2008.

\begin{tabular}{clrr}
\hline No. & \multicolumn{1}{c}{ Keterangan/Remarks } & $\begin{array}{c}\text { Kompor Minyak Tanah/ } \\
\text { Primus Stove }\end{array}$ & $\begin{array}{r}\text { Lampu Petromak/ } \\
\text { 'Petromak' Lamp }\end{array}$ \\
\hline 1 & Biaya Total (TC)/Total Cost & $54.830 .744,44$ & $47.270 .744,44$ \\
& a. Biaya Tetap (TFC)/Fixed Cost & $46.083 .600,00$ & $38.523 .600,00$ \\
& b. Biaya Variabel (TVC)/Variable Cost & $8.747 .144,44$ & $8.747 .144,44$ \\
2 & Biaya Investasi/Investment Cost & $91.592 .500,00$ & $91.592 .500,00$ \\
3 & Penerimaan Total (TR)/Total Revenue & $107.827 .200,00$ & $107.827 .200,00$ \\
4 & Keuntungan/Profit & $52.996 .455,56$ & $60.556 .455,56$ \\
5 & R-C Ratio & 1,97 & 2,28 \\
6 & Payback Period (Tahun)/Payback Period (Year) & 1,73 & 1,52 \\
\hline
\end{tabular}




\section{3. Analisis Kelayakan Finansial}

Berdasarkan hasil analisis finansial (Lampiran 1), maka diperoleh nilai NPV adalah sebesar Rp 695.550.355,5. Berarti jumlah keuntungan yang diperoleh selama 10 tahun yang dihitung berdasarkan nilai saat ini adalah sebesar Rp 695.550.355,5. Nilai Net B/C diperoleh sebesar 27,69 , yang artinya dari setiap satu rupiah biaya yang dikeluarkan akan menghasilkan manfaat sebesar RP 27,69 selama 10 tahun. Nilai IRR diperoleh sebesar $457,26 \%$, yang berarti usaha pembenihan ikan patin ini memberikan tingkat pengembalian sebesar $457,26 \%$ selama 10 tahun. Berdasarkan nilai-nilai yang dihasilkan, maka dapat dikatakan bahwa usaha pembenihan ikan patin dengan menggunakan petromak sebagai pemanas ruangan layak untuk dijalankan.

\subsection{Analisis Sensitivitas}

Hasil analisis sensitivitas menunjukkan bahwa apabila terjadi kenaikan harga pakan benih sebesar 1.228,65\%, (dari Rp 5.000,00/ kg menjadi Rp 61.432,50/kg), kenaikan harga minyak tanah sebesar $1.161,87 \%$ (dari harga Rp 7.000,00/liter menjadi Rp 81.330,90/liter) dan penurunan harga benih sebesar $98,57 \%$ (dari Rp 90,00 / ekor menjadi Rp 88,7/ekor dan $\operatorname{Rp} 375,00 /$ ekor menjadi Rp 368,64/ekor) maka usaha pembenihan ikan patin ini tidak layak untuk dijalankan.

\section{KESIMPULAN DAN IMPLIKASI KEBIJAKAN}

\section{Kesimpulan}

Penggantian alat pemanas dengan menggunakan lampu petromak pada kegiatan pembenihan ikan patin ini layak untuk diusahakan. Hal ini dapat dilihat dari hasil analisis kelayakan finansialnya menunjukkan hasil nilai NPV sebesar Rp 695.550.355,5, nilai Net B/C sebesar $27,69 \%$, nilai Net B/C $27,69 \%$ dan nilai IRR 457,26\%.

Usaha pembenihan ikan patin dengan menggunakan pemanas petromak akan menjadi tidak layak jika terjadi kenaikan harga minyak tanah sebesar $1.161,87 \%$, kenaikan harga pakan sebesar $1.228,65 \%$ dan penurunan harga benih sebesar $98,57 \%$. Dengan demikian, usaha pembenihan ikan patin ini tidak sensitif terhadap kenaikan harga minyak tanah, kenaikan harga pakan dan penurunan harga benih.

\section{Implikasi Kebijakan}

Kebijakan terkait dengan pengembangan budidaya usaha patin harus terus ditingkatkan karena budidaya tersebut telah memberikan manfaat yaitu menjadi alternatif usaha untuk peningkatan pendapatan pembudidaya ikan.

Kebijakan selanjutnya harus diarahkan kepada pemberian keringanan akses terhadap faktor produksi yang penting dalam usaha budidaya patin seperti harga BBM, harga pakan dan harga benih ikan.

\section{DAFTAR PUSTAKA}

BPPT. 2006. Biogas dan Penerapannya. Hasil Penelitian Tim Riset BPPT. Tidak dipublikasikan.

Effendi,I. dan W. Oktariza. 2006. Manajemen Agribisnis Perikanan. Penebar Swadaya. Jakarta.

Gittinger, J.P. 1986. Analisis Ekonomi ProyekProyek Pertanian. Sutomo $S$ dan $K$ Manggiri, penerjemah. Jakarta: Universitas Indonesia (UI Press). 579 hal.

Kadariah, L.K., C. Gray. 1978. Pengantar Evaluasi Proyek. Fakultas Ekonomi Yogyakarta.

Rahardi, F. N. dan R. Kristiawati. 2005. Agribisnis Perikanan. Penebar Swadaya. Jakarta .63 hal.

Sunarma. 2008. Trans-Regional Benih Patin. http:// www. Sunarma.net. indorcommunity. Wordpress.com. di Akses Tanggal 16 April 2008.

Susanto dan Amri. 1999. Budidaya Ikan Patin. Penebar Swadaya. Jakarta. $90 \mathrm{Hal}$. 


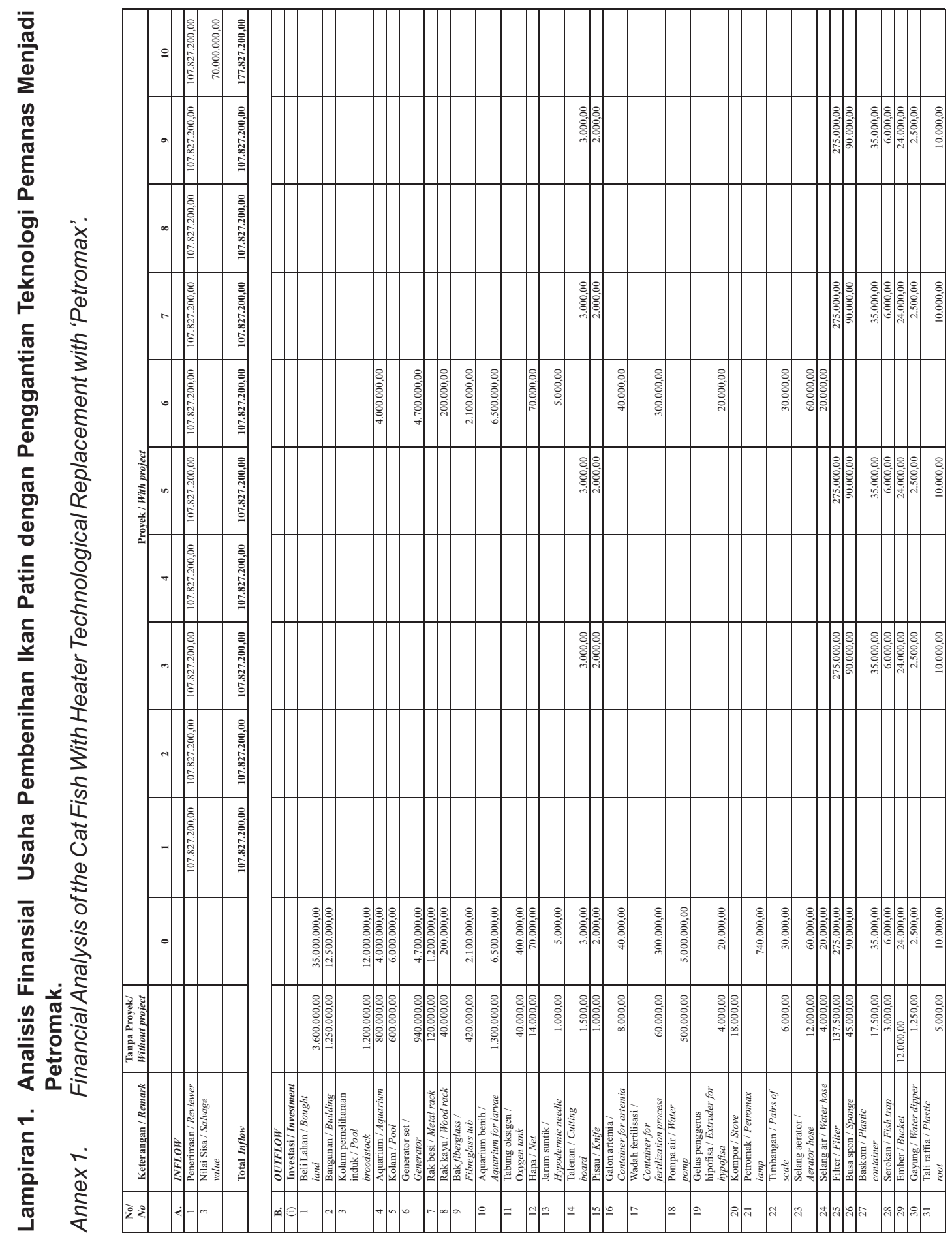




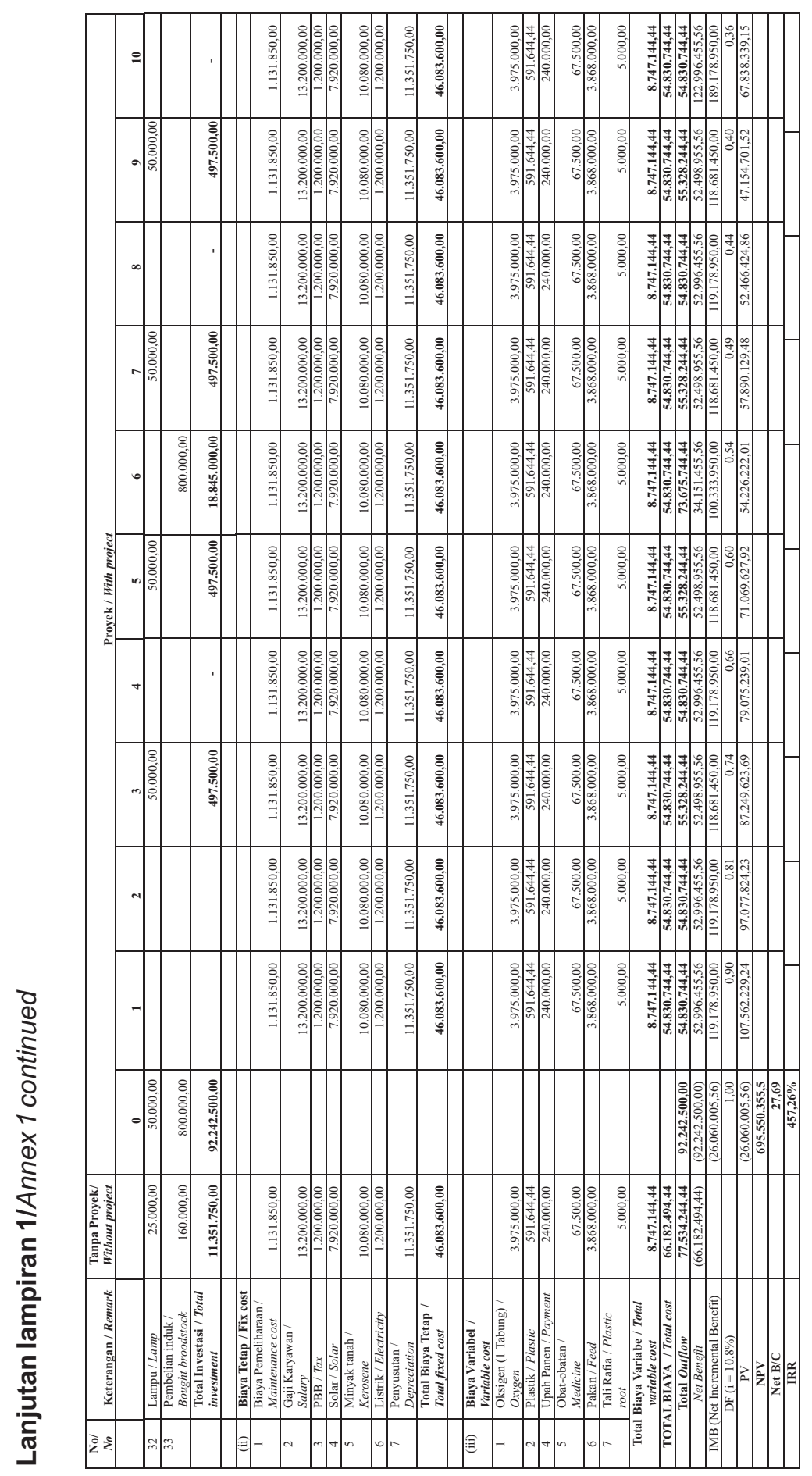

